\title{
Fragmentação na unidade: uma interpretação do feminino em Natália Correia
}

\author{
Fragmentation in unity: interpretation of the feminine in
}

Natália Correia's work

VÂNIA DUARTE (iDa

\section{Resumo}

A obra édita e inédita de Natália Correia faz, de forma inequívoca, a apologia do feminino. Um feminino fragmentado na procura da unidade, um feminino que se define herdeiro de cosmogonias primitivas e de correntes filosófico-religiosas sincréticas que ensaiaram a redefinição de um imaginário universal masculino. Também a proposta de uma Utopia Feminina do Espírito Santo, na senda da Teoria das Três Idades de Joachim de Fiore, comprova a vontade nataliana de reorganização de uma ordem simbólica masculina, culminando na reunificação do feminino e do masculino, no que a autora designa de "Frátria", muito na esteira do proposto por feministas como Simone de Beauvoir. Este artigo pretende, por conseguinte, apresentar as várias conceptualizações natalianas do feminino, numa perspetiva feminista.

Palavras-chave: Natália Correia. Espírito Santo. Frátria. Feminino.

\begin{abstract}
Natália Correia's published and unpublished work unequivocally evokes the feminine. A feminine fragmented in the search for unity, a feminine that defines itself as heritage of primitive cosmogonies and syncretic philosophical-religious currents that have rehearsed the redefinition of a universal masculine imaginary. Also, the proposal of a Feminine Utopia of the Holy Spirit, following Joachim de Fiore's Theory of the Three Ages, proves the writer's will to reorganize the symbolic masculine order, culminating in the reunification of the feminine and the masculine, in what the author calls "Frátria," very
\end{abstract}

\footnotetext{
a Universidade de Coimbra, Coimbra, Portugal. Mestra em Estudos Feministas, e-mail: vaniassenos@yahoo.com
} 
much in the wake of what feminists like Simone de Beauvoir proposed. This communication intends, therefore, to present the various conceptions of the feminine proposed by Natália Correia using a feminist theoretical framework.

Keywords: Natália Correia. Holy Spirit. "Frátria". Feminine.

\section{Introdução}

A obra édita e inédita de Natália Correia faz, de forma inequívoca, a apologia do feminino. Um feminino fragmentado na procura da unidade, um feminino que se define herdeiro de cosmogonias primitivas e de correntes filosófico-religiosas sincréticas, que ensaiaram a redefinição de um imaginário universal masculino. Também a proposta de uma Utopia Feminina do Espírito Santo, na senda da Teoria das Três Idades de Joachim de Fiore, comprova a vontade nataliana de reorganização de uma ordem simbólica masculina, culminando na reunificação do feminino e do masculino, no que a autora designa de "Frátria", muito na esteira do proposto por feministas como Simone de Beauvoir. Este artigo pretende, por conseguinte, refletir sobre as várias conceções do feminino em Natália Correia, numa perspetiva feminista.

\section{A Grande-Mãe e a "Mátria" nataliana}

Começo, então, por fazer referência ao livro de poemas “Mátria”, publicado em 1968, destacando a alusão a uma deusa do panteão iraniano, Anaíta. Ao longo deste poema o leitor depara-se com imagens belíssimas de união do masculino e feminino, em que se associa a Deusa a elementos como a água, que nas sociedades arcaicas simbolizava a fonte e origem de tudo (ELIADE, 1996, p. 151). O feminino constrói-se, portanto, associado à natureza, na esteira da veneração da Grande-Mãe. Note-se, a título de curiosidade, que Natália Correia além de se referir à deusa pelo seu nome, utiliza ainda o substantivo "matrona". Segundo Raphael Patai, "matronit" foi o termo utilizado, no século XIII, pelos cabalistas judeus para designarem o aspeto feminino de Deus. 
Outras deusas são também elencadas, como Inanna, do panteão sumério, como podemos verificar ao ler o prefácio da antologia poética $A$ mulher, publicado em 1973. Esta surge associada a Ereshkigal, sua irmã, para indicar a dualidade a que esteve votado o universo feminino, em contraponto com o universal aristotélico neutro, que se torna norma (HENRIQUES, 2010, p. 19). Nesse mesmo prefácio, a autora faz ainda referência ao mito de Eros e Psiquê, destacando a capacidade que a mulher tem de, através da paixão, fazer revelar no homem tanto o "sublime" como o "ignóbil”. Porém, a autora realça que ao ter adquirido esta capacidade transformadora do eu masculino, a mulher teve de se transformar no outro, afastando-se, portanto, da sua origem cosmogónica, geradora partenogénica dos princípios feminino e masculino.

Natália Correia, projeta, assim, numa primeira fase uma "Mátria", associando a mulher a forças naturais, restaurando o poder das grandesdeusas e resgatando o feminino da cultura patriarcal que o tem sonegado. Ao ser questionada sobre o que entende por "matrismo", em entrevista a Antónia de Sousa, em 1983, a autora afirma:

-Bom... Acho que não vale a pena a mulher libertar-se para imitar os padrões patristas que nos têm regido até hoje. [...] Ora bem, a mulher deve seguir as suas próprias tendências que estão intimamente ligadas ao paradigma da Grande Mãe, que é a grande reserva, a eterna reserva da Natureza, precisamente para os impor ao mundo ou pelo menos para os introduzir no ritmo das sociedades como uma saída indispensável para os graves problemas que temos e que foram criados pelas racionalidades masculinas. É no paradigma da Grande Mãe que vejo a fonte cultural da mulher; por isso lhe chamo matrismo e não feminismo (SOUSA, 2004, p. 65).

\section{A Utopia Feminina do Espírito Santo}

Outras configurações do feminino se apresentam ainda, como é o caso da proposta nataliana de uma utopia feminina do Espírito Santo, assente na doutrina das Três Idades de Joachim de Fiore, descrita pela própria da seguinte forma:

A doutrina Joaquimita proclamava a presença do espírito na história que dividia em três idades. A do pai, a da lei de Moisés que acabava com Cristo, cuja história vinha narrada no Antigo Testamento. Era a Idade da Servidão. A segunda idade, a do Filho, começara com Cristo e correspondia ao Novo Testamento. Era a idade da obediência filial que terminaria com o advento do Espírito Santo. Nesta 
terceira Idade, que seria a da liberdade, o Espírito Santo viria substituir-se ao poder da Igreja corrupta e decadente. O seu evangelho seria o livro de que S. João fala no Apocalipse, o Evangelho Eterno [...] (FRANCO; MOURÃO, 2005, p. 153).

Analogamente, Natália Correia propõe a emergência de uma era de libertação, mas sob o signo do feminino, partindo do arquipélago açoriano como ponto de análise socio-histórica. Em A transposição açoriana do Portugal europeu, Natália Correia debruça-se precisamente sobre as causas do enraizamento da teoria joaquimita nos Açores, cujos resquícios ainda são visíveis nas práticas locais, justificando que a sua propagação a nível insular foi adjuvada pelo seguintes fatores: o comunitarismo inerente à organização social, o municipalismo e a própria circunstância de insularidade.

A mulher, por exemplo, possuía um estatuto social diferenciado que faz eco dos matriarcados da antiguidade, como salienta Natália Correia, baseada no Padre Júlio da Rosa. Aliás, a autora constata ainda que a figura da Imperatriz, coroada nas festividades açorianas, fora expressamente proibida pelo Bispado de Angra em 1559, infrutiferamente.

\footnotetext{
O tipo de religiosidade do povo açoriano deriva das mesmas raízes comunitárias e feministas que investiram a mulher da superioridade que desfruta nos Açores. Feministas? Vejamos, será altura de relembrar que o Espírito Santo é feminino nas línguas semitas - Ruha Kadesh em hebraico, Ruh Rurr em aramaico (o actual siríaco), sendo, como me informa o dominicano Emanuel Siman, o verbo posto no feminino quando se fala do espírito e da sua relação com os cristãos. Importa ainda sublinhar que esta feminização da Terceira Pessoa da Trindade está configurada na imperatriz que, a par do imperador, figura no rito. [...] Leiam-se as Constituições do Bispado de Angra de 1559, em que se põe como condição para a realização da festa dos Imperadores: "Contanto que não haja imperatriz juntamente" (FRANCO; MOURÃO, 2005, p. 181).
}

Repare-se na alusão ao Padre Emmanuel-Pataq Siman, mencionado neste excerto, propalador da tese de o Espírito Santo ser feminino, à semelhança de outros nomes destacados por Natália Correia, como Catharina Halkes que nos remetem para a influência da teologia feminista no seu próprio ideário.

\section{O andrógino e a "Frátria"}

No documento $n^{\circ}$ 4042, que pode ser consultado na Biblioteca Pública e Arquivo Regional de Ponta Delgada, intitulado "O feminino, o herético e o 
erótico", Natália Correia aborda a questão do andrógino, tema que será fulcral no entendimento não da Mátria, inicialmente apontada, mas de uma Frátria. Neste mesmo documento faz remontar a questão do andrógino à narrativa bíblica, referindo-se em particular à passagem do Génesis, pois “ali se diz que criou o macho e fêmea à sua semelhança" (CORREIA, n 4042, p. 1), inferindose, portanto, que Deus era concomitantemente masculino e feminino. Como, logo em seguida, decidiu dar primazia ao masculino, estabelecendo-se então uma hierarquia que subjugava a mulher, a serpente, "figuração ginecocrática, atributo das Deusas Mãe" (CORREIA, n 4042, p. 1), insurge-se contra a ordem estabelecida:

Como não havia a usurpada serpente de revoltar-se contra a ordem falocrática, autoritária de Jeová que, inferiorizando o feminino do par humano primordial, o privava da integridade que possibilita o conhecimento do mundo? Conhecimento conexo com a união sexual, diga-se, pois que regenera a unidade configurada na androginia do Ser Supremo. Revestido o sexo de mortal pecaminosidade, condenados aos tormentos são Adão e Eva, e amaldiçoada é a serpente que os iniciou no mistério da união sexual concebida à luz de uma teologia da polaridade feminina da Divindade hermafrodita (CORREIA, $n^{\circ} 4042$, p. 1).

Deste excerto destaco três aspetos importantes: o primeiro, em que a autora atribui à união sexual um caráter sagrado; um segundo ponto que se prende com a identificação explícita da existência de uma "teologia da polaridade feminina da Divindade hermafrodita", que nos remete para religiões ou correntes em que o princípio feminino se sobrepõe ao masculino; e, por último, a referência a uma ordem simbólica "falocrática", a que Natália Correia também se opõe e ousa des/reconstruir.

Reforço a importância da asserção "teologia da polaridade feminina da Divindade Hermafrodita", pois na validação de uma frátria andrógina, Natália Correia advoga o predomínio do feminino. Tal não implica, porém, a subjugação do masculino, mas sim a constatação de que um dos polos é, pelos seus atributos e funções, distinto e fundamental, pois é ele o elemento que medeia e conduz à realização plena.

É ainda de crer que Natália Correia remontaria a proveniência conceptual do ser andrógino às especulações gnósticas, influindo ao longo dos 
séculos em variegados movimentos religioso-filosóficos, sendo possível rastreá-lo até ao culto do Espírito Santo.

\section{Confluências teóricas feministas}

A fraternidade andrógina aqui aludida não deixa, contudo, de ecoar as teorias beauvoirianas. Megan M. Burke, em artigo publicado recentemente, analisa precisamente a fraternidade andrógina de Beauvoir, propondo que a feminista francesa não pretendia, na sua conceptualização de um futuro andrógino, diluir as diferenças sexuais, mas sim, partindo dessa diferença, ou estado, pensar uma sociedade outra.

Se estabelecermos um paralelo com Natália Correia, podemos inferir que a utilização do termo "frátria" não é, portanto, aleatória e que a influência teórica de Simone de Beauvoir parece-me cabal na escolha do termo "Frátria”, não descartando, porém, outras fontes como o gnosticismo, o misticismo judaico ou a alquimia. Repare-se que Beauvoir era assaz conhecida em Portugal na segunda metade do século XX. Por altura da publicação de Novas Cartas Portuguesas pelos Estúdios Cor, cuja diretora literária era Natália Correia, e subsequente condenação das três Marias, Beauvoir fez parte de um movimento de apoio às escritoras portuguesas, manifestando-se inclusive em frente à embaixada portuguesa, em Paris, o que comprova o contacto existente entre os círculos feministas franceses e os portugueses. Repare-se ainda que o tema do andrógino teve grande impacto na sociedade francesa em inícios do século XIX, por influência de correntes utópicas que resgataram a natureza dupla do homem primordial, assim como o orfismo, o gnosticismo e a filosofia hermética (PINKUS, 2010, P. 59). No que concerne à crítica feminista, este tema teve ainda grande impacto académico, sendo assaz debatido por feministas de vários quadrantes e épocas: Iris Young, Irigaray, entre outras, opunham-se à idealização de um futuro andrógino como solução ou estratégia para se atingir a tão ansiada igualdade entre mulheres e homens, pois anularse-iam as diferenças, nomeadamente os atributos comumente atribuídos ao sexo feminino. Também Elaine Showalter e Toril Moi se debruçaram sobre o tema, ao posicionarem-se criticamente face à androginia defendida por Virgina Woolf em A Room of One's Own, já anteriormente esboçada em Orlando. 
Showalter tece duras críticas à idealização do espaço andrógino woolfiano, destacando a polarização essencialista sexual (SHOWALTER, 1977, p. 264), justificando a sua idealização como uma forma de Woolf se confrontar com a sua própria feminilidade e considerando a androginia artística ou literária de Woolf como um projeto utópico (SHOWALTER, 1977, p. 289).

Moi, por seu lado, destaca a descontrução do unitarismo do eu levada a cabo tanto por Virginia Wolf como por Doris Lessing, posicionando-se exatamente nos antípodas do propalado por Showalter. Um outro aspeto de particular interesse, referido por Toril Moi, prende-se com a seguinte afirmação: "Woolf rejects the metaphysical essentialism which forms the basis of patriarcal ideology, which hails God, the Father or the phallus as its transcendental signifier" (MOI, 2004, p. 9). Vale a pena estabelecer um paralelo com Natália Correia, na medida em que o Espírito Santo é substituído pelo Espírito Santo feminino, propondo, assim, Natália Correia um significante universal transcendente feminino, e não masculino, numa tentativa de reconfigurar a ordem simbólica instituída.

Por conseguinte, à luz de uma hermenêutica feminista, como poderíamos definir Natália Correia? Beauvoir, em O segundo sexo, descreve a história da mulher ou mulheres, atribuindo-lhes um papel secundário, não sujeito, mas outro, idealizando, como forma de ultrapassar as diferenças, uma fraternidade andrógina. No que respeita o nosso objeto de estudo, a obra literária de Natália Correia revela um passado feminino subjugado ao patriarcado, podendo a mulher ser, por essa razão, entendida como o "outro". Porém, no seu empenho em criar um imaginário novo, através do qual a mulher se assume protagonista da sua própria história, Natália Correia povoa os seus poemas e romances com deusas heroínas, personagens mulheres cujo poder é natural e intemporal, daí a impossibilidade de as reduzir a um papel de submissão e de alteridade.

\section{Considerações finais}

A meu ver, a androginia nataliana é uma metáfora de libertação (também sexual) e uma tentativa de reconfigurar a ordem simbólica masculina. Note-se que a libertação que Natália Correia tanto anseia 
transcende o sexo, não se limita a querer a realização plena da mulher, mas sim a plenitude do ser que assim transcende a sua condição humana e sexuada. Um outro aspeto que me parece fundamental destacar mais uma vez é o papel fundamental que o feminino desempenha na libertação da sua imanência; é pela diferença que se dá a ascese, pelo que é impossível eliminá-lo.

O contributo de Natália Correia para uma narrativa feminista é inegável por tudo o que aqui já foi apontado. Contudo, é importante ressalvar que a sua própria construção desta mesma narrativa foi sendo escrita e reescrita à sombra de um legado cuja figura dominante é a figura do pai e a qual a escritora conscientemente quis subverter, enaltecendo, por conseguinte, o feminino nas suas mais variadas formas: a Grande-Mãe, o espírito santo feminino ou o andrógino.

\section{Referências}

BEAUVOIR, S. de. O segundo sexo: a experiência vivida. São Paulo: Difusão Européia do Livro, 1967.

BEAUVOIR, S. de. O segundo sexo: fatos e mitos. São Paulo: Difusão Européia do Livro, 1970.

BURKE, M. M. Beauvoirian Androgyny: Reflections on the Androgynous World of Fraternité in The Second Sex. Feminist Theory, v. 20, n. I, p. 3-18, 2019.

DOCUMENTO n 4042 do espólio de Natália Correia, que pode ser consultado na Biblioteca Pública e Arquivo Regional de Ponta Delgada.

ELIADE, M. Imagens e símbolos. Ensaios sobre o simbolismo mágico-religioso. São Paulo: Martins Fortes, 1996.

FRANCO, J. E.; MOURÃO, J. A. A Influência de Joaquim de Flora em Portugal e na Europa. Escritos de Natália Correia sobre a utopia da idade feminina do Espírito Santo. Lisboa: Roma Editora, 2005.

HENRIQUES, F. Concepções filosóficas e representações do feminino: Subsídios para uma hermenêutica crítica da tradição filosófica. Revista Crítica de Ciências Sociais, Coimbra, v. 89, p. 11-28, 2010.

MOI, T. Sexual/Textual Politics. Feminist Literary Theory. In: Taylor \& Francis e-Library, 2004 .

PATAI, R. The Hebrew Goddess. Detroit: Wayne State University Press, 1990. 
PINKUS, K. Alchemical Mercury: A Theory of Ambivalence. California: Stanford University Press, 2010.

SHOWALTER, E. A Literature of Their Own. British Women Novelists from Brontë to Lessing. Princeton: Princeton University Press, 1977.

SIMAN, E.-P. L'experience de l'esprit par l'église d'après la tradition d'Antioche. Paris: Éditions Beauchesne, 1971.

SOUSA, A. et al. Entrevistas a Natália Correia. Lisboa: Parceria A. M. Pereira, 2004.

RECEBIDO: $30 / 10 / 2020$

RECEIVED: $10 / 30 / 2020$

APROVADO: 22/03/2021

APPROVED: 03/22/2021 